\title{
Michael Wolter
}

\section{Theologie und Ethos im frühen Christentum}

\author{
Studien zu Jesus, Paulus und Lukas
}

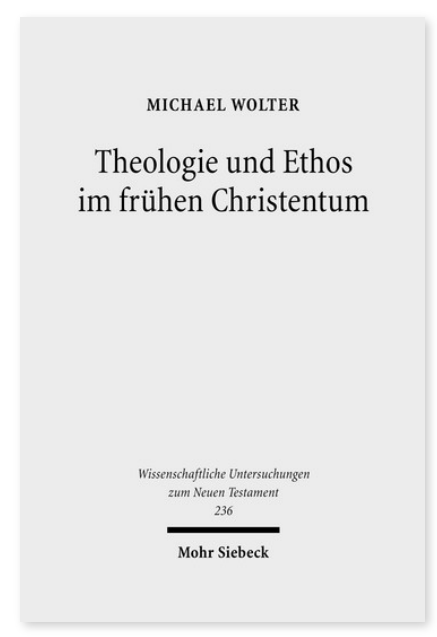

2009. X, 539 Seiten. WUNT I 236

SBN 978-3-16-151525-5

DOI 10.1628/978-3-16-151525-5

eBook PDF 159,00€

ISBN 978-3-16-149903-6

Leinen $159,00 €$
Michael Wolter legt Untersuchungen zu zentralen Themen der Verkündigung Jesu, zur Theologie des Apostels Paulus sowie zur Geschichtstheologie des lukanischen Doppelwerks vor. Dabei arbeitet er heraus, dass es eine deutlich identifizierbare theologische Kontinuität von Jesus über Paulus zu Lukas gibt. Gleichzeitig machen die Studien aber auch sichtbar, wie erst Paulus und dann Lukas neue theologische Akzente setzen, um die Eigenart der christlichen Botschaft für die Gemeinden ihrer Zeit jeweils neu zur Sprache zu bringen. Als Mitte der Verkündigung Jesu von Nazareth gilt Jesu Anspruch, authentischer Repräsentant von Gottes heilvoller Zuwendung zu Israel zu sein. Paulus entwickelt das theologische Konzept einer christlichen Identität und eines ihr entsprechenden christlichen Ethos, die allein auf dem Glauben an Jesus Christus basieren. Im Mittelpunkt des Paulusteils steht eine längere Untersuchung, in der es darum geht, den engen Zusammenhang von Theologie und Ethos bei Paulus herauszuarbeiten. Dabei wird die Ethik als »angewandte Ekklesiologie« verstanden. Bei Lukas schließlich steht das Bemühen im Vordergrund, die Geschichte Jesu und die Geschichte der Trennung von Christentum und Judentum als integralen Bestandteil der Geschichte Israels verständlich zu machen. Sein von Lk 1 bis Apg 28 reichendes Geschichtswerk ist als »Epochengeschichte« konzipiert, die eine in sich abgeschlossene Epoche der Geschichte Israels behandelt. Übergreifende Studien zur Apokalyptik, zur Geschichte des Gesetzesbegriffs im frühen Christentum und zum Sündenverständnis vervollständigen das Buch.

Michael Wolter is Professor of New Testament at the Faculty of Protestant Theology at the University of Bonn in Germany and Honorary Professor at the Theological Faculty at the University of Pretoria in South Africa.
Jetzt bestellen:

https://mohrsiebeck.com/buch/theologie-und-ethos-im-fruehen-christentum-9783161515255?no_cache=1 order@mohrsiebeck.com

Telefon: +49 (0)7071-923-17

Telefax: +49 (0)7071-51104 